CONF-851174--24

CONF-851174--24

DE86 004682

PREDICTION OF FLOW RATES THROUGH AN ORIFICE AT PRESSURES CORRES ONDING TO THE TRANSITION BETWEEN

MOLECULAR AND ISENTROPIC FLOW

S. F. DeMuth

Fuel Recycle Division

and

J. S. Watson

Chemical Technology Division

Oak Ridge National Laboratory*

Oak Ridge, Tennessee 37831

and

Department of Chemical Engineering

University of Tennessee

Knoxville, Tennessee 37916

For inclusion in the proceedings of the

32nd National Symposium of the

American Vacuum Society

November $19-22,1985$

Houston, Texas

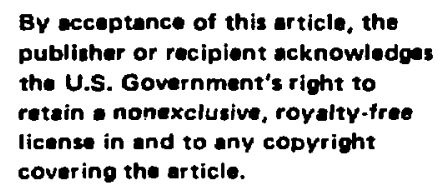

*0perated by Martin Marietta Energy Systems, Inc., for the U.S. Depariment of Energy. 


\title{
PREDICTION OF FLOW RATES THROUGH AN ORIFICE AT PRESSURES \\ CORRESPONDING TO THE TRANSITION BETWEEN \\ MOLECULAR AND ISENTROPIC FLOW*
}

\author{
S. F. DeMuth, Fuel Recycle Division \\ J. S. Watson, Chemical Technology Division \\ nak Ridge National Laboratory \\ Oak Ridge, Tennessee 37831 \\ and \\ Department of Chemical Engineering \\ University of Tennessee \\ Knoxville, Tennessee 37916
}

\begin{abstract}
A model of compressible flow through an orifice, in the region of transition from free molecular to isentropic expansion flow, has been developed and tested for accuracy. The transitional or slip regime is defined as the conditions where molecular interactions are too many for free molecular flow modeling, yet not great enough for isentropic expansion flow modeling. Due to a lack of literature establishing a well-accepted model for predicting transitional flow, it was felt such work would be beneficial. The model is nonlinear and cannot be satisfactorily linearized for a linear regression analysis. Consequently, a computer routine was developed which minimized the sum of the squares of the residual flow for the nonlinear model. The results indicate an average accuracy within $15 \%$ of the measured flow throughout the range of test conditions. Furthermore, the results of the regression analysis indicate that the transitional regime lies between Knudsen numbers of approximately 2 and 45.
\end{abstract}

*Research sponsored by the Office of Uranium Enrichment, U.S. Department of Energy, under Contract No. DE-AC05-840R21400 with Martin Marietta Energy Systems, Inc. 


\section{INTRODUCTION}

A model of compressible flow through an orifice, in the region of transition from free molecular to isentropic expansion flow, has been developed and tested. The model is based loosely upon theoretical considerations for combining the free molecular and isentropic expansion models, but it is largely empirical. It was felt that such work would be important because there was no well-accepted model for predicting flow under these conditiors.

The proposed model is of a nonlinear form which cannot be satisfactorily linearized for a linear regression analysis. Consequently, a computer routine was developed for a nonlinear regression analysis which minimized the sum of the squared residuals of the flow rates. The resulting model predicted flow within $15 \%$ of the measured flow throughout the transitional region. Additionally, the results of the regression analysis indicate that the transitional region for orifice flow lies between Knudsen numbers of approximately 2 and 45 for the range of test conditions. The proposed model was compared with the best alternate model selected from the literature and was found to be more accurate over the range of conditions tested. This accuracy was obtained with the use of only a single regression coefficient, whereas the best alternate model from the literature required tivo regression coefficients.

\section{THEORETICAL}

\subsection{Prior Mode1s}

Previous models have had limited success predicting transitional flow in orifices. Two documented models of particular interest were 
proposed by Parker and Santeler, ${ }^{1}$ and by Borisov et $a 1 .^{2}$ These models are described by Eqs. (1) and (2) respectively.

$$
Q_{t}=a Q_{m}+C_{1}(1-a) Q_{i},
$$

where

$$
\begin{aligned}
& a \quad=\text { function of transitional boundary pressures, } \\
& C_{1} \quad=A^{\prime}\left(1-B^{\prime} / P^{x}\right), \\
& A^{\prime}, B^{\prime}=\text { regression coefficients, } \\
& x \quad=0.05 . \\
& Q_{t}=\left(1+C K^{\prime}\right) Q_{m},
\end{aligned}
$$

where

$$
\begin{aligned}
& K^{\prime}=\text { function of system pressure, } \\
& C=\text { regression coefficient. }
\end{aligned}
$$

The variables $Q_{m}$ and $Q_{i}$ are the free molecular orifice flow and isentropic expansion models defined in most texts addressing vacuum technology [see Eqs. (3.71) and (3.30) of ref. 3].

The Parker-Santeler model was originally validated by tests using $\mathrm{UF}_{6}$ in the high pressure region of transitional flow. The coefficient "a" in Eq. (1) is defined to be a function of the estimated transitional boundary pressures, and the coefficient $C_{1}$ is a type of orifice coefficient dependent on the system pressure.

Equation (2), which was developed by Borisov et al., applies primarily to the low pressure region of transitional flow. This is readily obvious due to the incorporation in the model of only the molecular flow contribution. The coefficient $\mathrm{C}$ is determined empirically, and $\mathrm{K}^{\prime}$ is a type of modified inverse Knudsen number. 


\subsection{Proposed Model}

If the free molecular and isentropic expansion models are plotted at a constant pressure ratio as shown in Fig. 1 , the logarithm of the flow rate is linearly dependent on the logarithm of the upstream pressure. The goal of a transitjonal flow model should be to bridge the free molecular and isentropic models in the region of transitional flow. Therefore, some type of curve spans this region as depicted by $Q_{t}$ in Fig. 1. The model proposed in this paper made use of an asymptotic transition from the free molecular to isentropic model as the Knudsen number or system pressure increased. A single regression coefficient was used to define this transition as defined by Eq. (3):

$$
Q_{t}=Q_{m}+\left(Q_{i}-Q_{m}\right)\left(1-C_{a}^{-K}\right) \text {. }
$$

The regression coefficient, $C_{a}$, physically represents the reciprocal of the probability that a molecule, after colliding with another molecule, will not be swept through the orifice. Since the Knudsen number is proportional to the number of collisions expected when a molecule traverses a distance equivalent to the size of the orifice, $\mathrm{C}_{\mathrm{a}}^{-\mathrm{K}}$ is an approximation for the probability that a molecule would avoid being diverted through the orifice when traveling a distance equivalent to the orifice diameter.

Using the coefficient $\mathrm{C}_{\mathrm{a}}$ in Eq. (3) allows one to define the boundaries over which the transition from free molecular to isentropic expansion occurs. If the molecular to transitional boundary is defined to occur at $90 \%$ free molecular flow and $10 \%$ isentropic expansion flow, then the Knudsen number equivalent to this boundary can be expressed by

$$
\begin{gathered}
0.9 Q_{m}+0.1 Q_{i}=Q_{m}+\left(Q_{i}-Q_{m}\right)\left(1-C_{a}-K_{m}\right), \text { or } \\
K_{m}=[\ln (10 / 9)] / \ln \left(C_{a}\right) .
\end{gathered}
$$




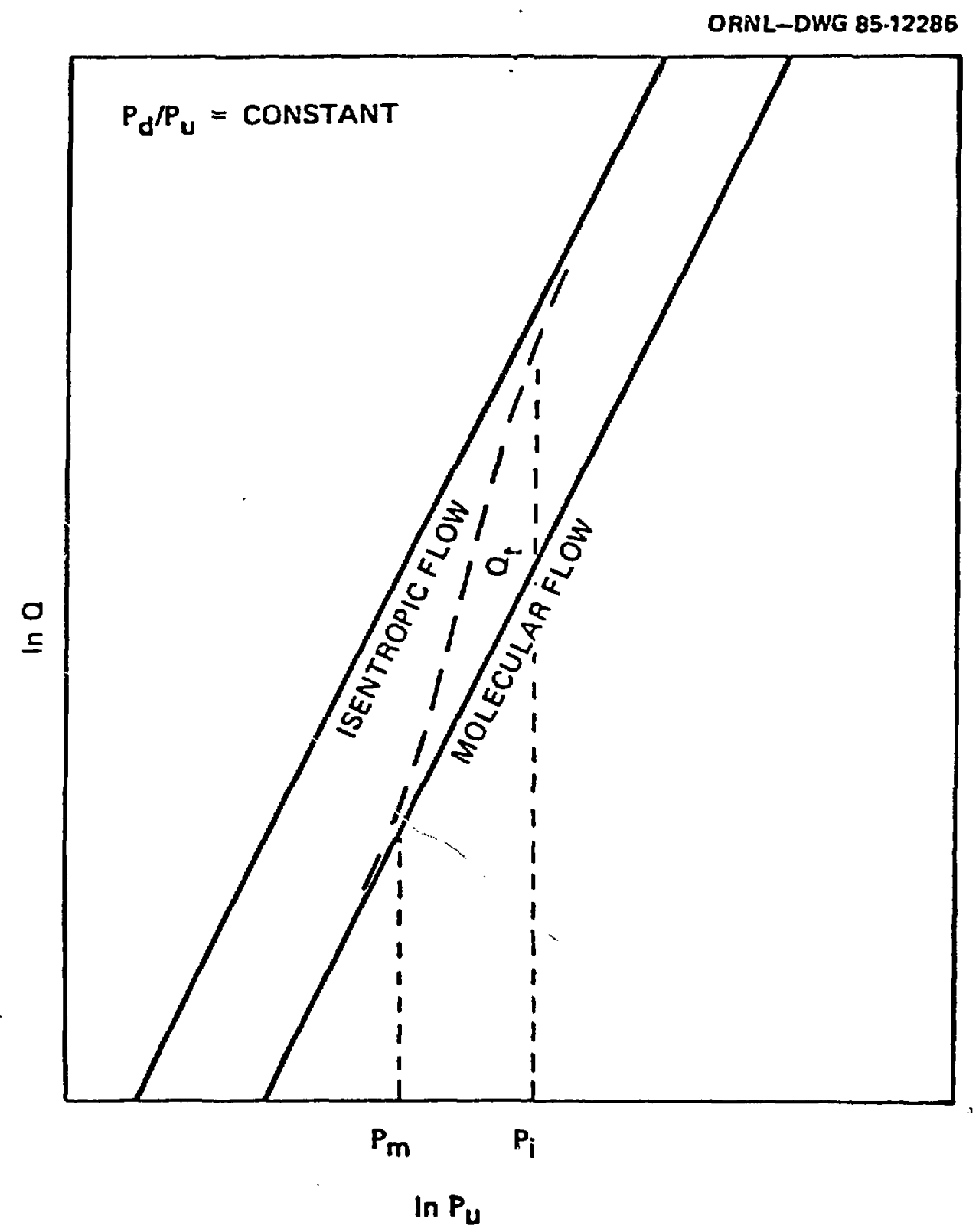

Figure 1. Molecular and isentropic model at a constant pressure ratio. 
Similarly, the isentropic boundary can be defined as $10 \%$ free molecular. flow and 90\% isentropic flow as shown by Eq. (5).

$$
K_{i}=[\ln (81)] /\left[2 \ln \left(C_{2}\right)\right] \text {. }
$$

For the case of the 10 to $90 \%$ boundary, $K_{i} / K_{m}=20.85$, and this ratio is independent of $\mathrm{C}_{2}$.

\subsection{Regression Analysis}

The basis for any linear regression is a normal distribution of the dependent variable about the independent variable. Since $Q_{i}$ is related to the pressure (independent variable) in a nonlinear manner, any linearization of Eqs. (1) or (3) would disrupt the normal distribution of the dependent variable (flow rate) about the independent variable. For this reason, the madels were evaluated using a nonlinear regression analysis which minimized the sum of the squared flow residuals.

The conventional techniques for determining the confidence intervals of the regression coefficients were not applicable to this nonlinear analysis. Therefore, the functional dependency of the regression coefficient upon the error in the residuals was determined by Eq. (6) for the proposed model.

$$
W_{\mathrm{Ca}}=\left[\left(\partial \mathrm{Rs} / \partial \mathrm{C}_{\mathrm{a}}\right)^{2} \mathrm{~W}_{\mathrm{Rs}}{ }^{2}\right]^{1 / 2} \text {, }
$$

where

$$
\begin{aligned}
& W=\text { uncertainty } \\
& \text { Rs }=100\left\{\left[Q_{t} \text { (calculated) }-Q_{t} \text { (measured) }\right]^{2} /\left[Q_{t} \text { (measured) }\right]^{2}\right\}^{1 / 2} .
\end{aligned}
$$

The confidence intervals for the residuals were estimated by combining three properly weighted normal distributions, each representing an individual data set. 


\section{EXPERIMENTAL}

The test setup pictured in Fig. 2 was used to collect the experimental data for the flow of ambient air. The flow meter consisted of a liquid-filled buret for direct volumetric measurements of the accumulated volume of gas at barometric pressure. A 2-mL and a 10-mL maximum displacement buret were used to cover the entire range of flow conditions. Capacitance manometer pressure sensors of $10^{-5}$ and $10^{-3}$ torr minimum sensitivity were used to measure the pressure. The vacuum pumping system consisted of a $230-\mathrm{L} / \mathrm{s}$ diffusion pump backed by a $17-\mathrm{cfm}$ rotary vane mechanical pump. The diffusion pump was not operated with an inlet pressure above 0.2 torr. The throttle valves consisted of a fine controlling nesdle valve upstream of the orifice (minimum adjustable flow was approximately $10^{-10}$ torr-L/s as specified by the vendor) and a coarse plug valve downstream of the orifice. Both values required adjustment for each data point in order to obtain both the desirable upstream pressure and the differential pressure. Each orifice was made of a polymeric film of $0.20 \mathrm{~mm}$ thickness, mounted on a brass ring support.

The data were divided into three sets which investigated the effect of the orifice diameter and the pressure ratio upon the regression coefficients. The first data set consisted of data collected with a $1.27-\mathrm{mm}$ orifice diameter and a pressure ratio of 0.9 . The second data set also contained data based on the $1.27-\mathrm{mm}$ orifice but with a pressure ratio of 0.7 . The third data set contained data collected with a $2.44-\mathrm{mm}$ orifice and a pressure ratio of 0.9 . 
DWG. NO. K/O-94-210

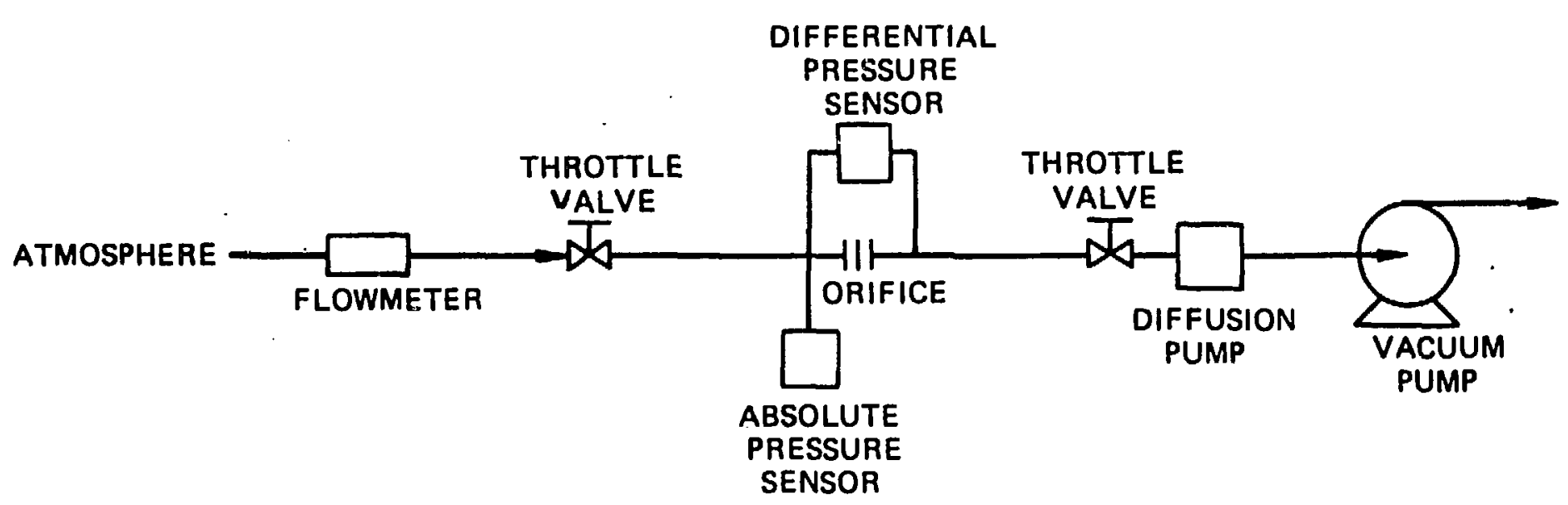

Figure 2. Test setup 
Estimates of the experimental error in the data were found to average $\pm 2 \%$ according to the uncertainty analysis expression, Eq. (7).

$$
W_{Q}=\left[\left(\frac{\partial Q}{\partial p_{b}}\right)^{2} W_{p_{b}}^{2}+\left(\frac{\partial Q}{\partial v_{b}}\right)^{2} w_{v_{b}}{ }^{2}+\left(\frac{\partial Q}{\partial t}\right)^{2} w_{t}{ }^{2}\right]^{1 / 2} \text {. }
$$

\section{RESULTS AND DISCUSSION}

The proposed model regression curve is shown with the data collected in Fig. 3. The regression coefficient, $C_{a}$, was found to be 1.05 , and thus the best equation describing the data was

$$
Q_{t}=Q_{m}+\left(Q_{i}-Q_{m}\right)\left(1-1.05^{-K}\right) \text {. }
$$

A visual examination of Fig. 3 shows that the proposed mudel fits the data we11.

The Parker-Santeler model was curve fit to the same data used to establish the regression coefficient of the proposed model. The high pressure range of the Parker-Santeler data made comparisons with the current model difficult. Comparisons of the new proposed model and the results of a linear regression of the Parker-Santeler model using all three data sets from this study are shown in Table 1 . The accuracy is reported as the average percent residual flow; this has the advantage over the sum of the squared residuals of more evenly weighting the flow over several orders of magnitude.

The confidence intervals of the proposed model flow residuals were estimated by combining the properly weighted normal distributions of each data set. The combined distribution, which was similar to a Poisson distribution, was then numerically integrated to estimate the confidence levels. Once a value for the confidence levels of the 


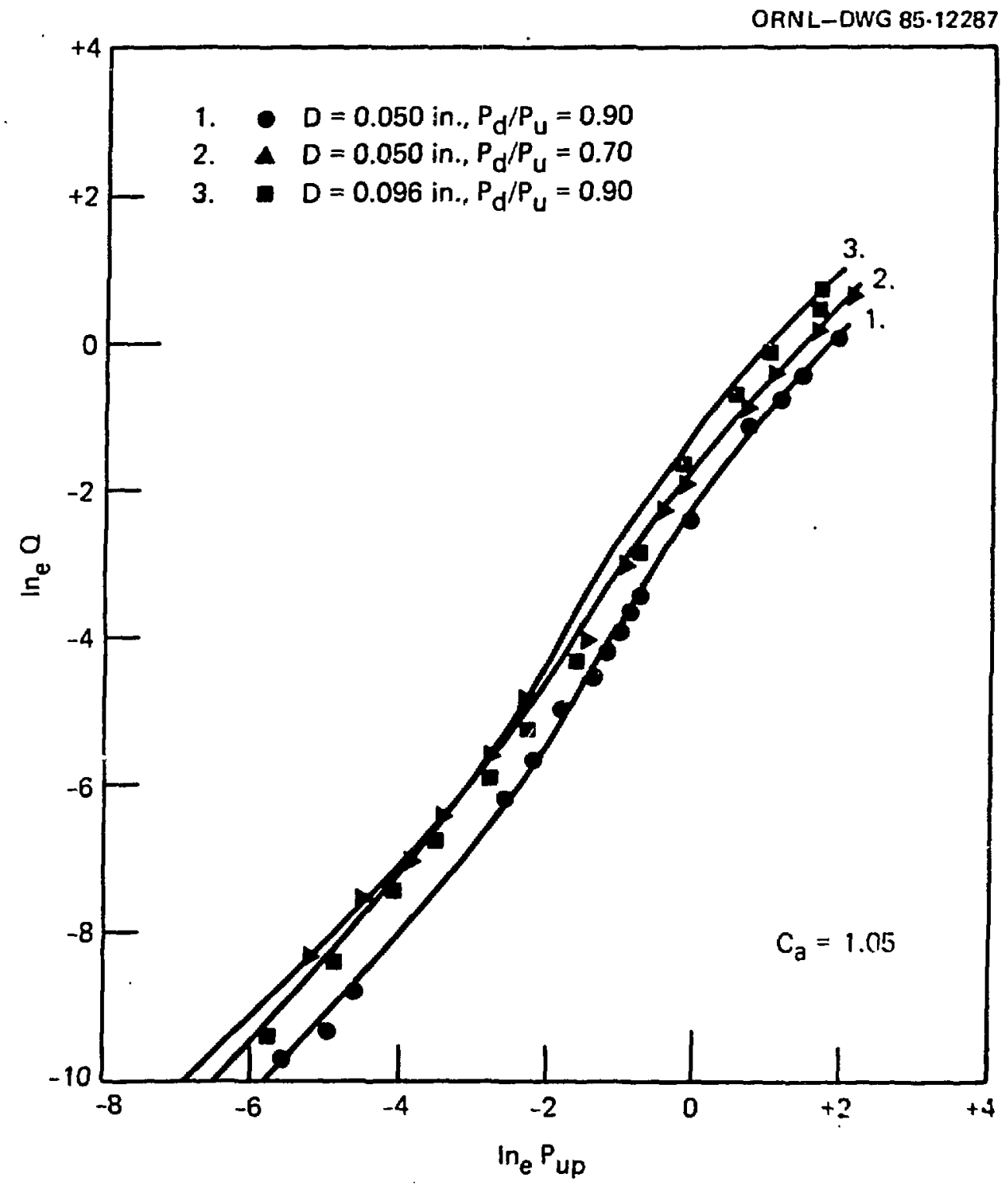

Figure 3. Proposed probability model. 
Table 1. Regression analysis results

\begin{tabular}{|c|c|c|c|c|c|}
\hline \multirow[b]{2}{*}{ Data set } & \multicolumn{3}{|c|}{$\begin{array}{l}\text { Proposed model } \\
\text { Eq. (3) }\end{array}$} & \multicolumn{2}{|c|}{$\begin{array}{c}\text { Alternate model } \\
\mathrm{Eq} .(1) \\
\end{array}$} \\
\hline & $\mathrm{C}_{\mathrm{a}}$ & $r^{*}$ & $\overline{A^{\prime}}$ & $B^{\prime}$ & $r$ \\
\hline Collective & 1.05 & 14.8 & 0.998 & -0.106 & 21.1 \\
\hline One & 1.061 & 15.2 & 0.996 & -0.136 & 22.7 \\
\hline Two & 1.079 & 7.6 & 0.996 & -0.189 & 8.3 \\
\hline Three & 1.021 & 11.7 & 1.004 & -0.045 & 30.4 \\
\hline
\end{tabular}

Note: See ref. 4 for the particulars of the regression analysis.

${ }^{*} r=(1 / n) \sum_{j=1}^{n} R s_{j}$. 
residual error was determined, the error was translated to the regression coefficient by Eq. (6).

As shown in Table 1, the average percent residual flow of the proposed model for the collective data set is $15 \%$ as compared to $21 \%$ for the Parker-Santeler model. This indicates that when using the proposed model, Eq. (3), the average accuracy can be expected to be $15 \%$ of the true flow. There is $53 \%$ confidence that the accuracy of the proposed model is within $15 \%$ ( $15 \%$ is the average residual error) of the measured flow; there is $82 \%$ confidence that the accuracy is within twice the average residual error.

A comparison of the individual data sets shows that regression coefficients do vary, 1.021 to 1.079 for $\mathrm{C}_{\mathrm{a}}$ in the proposed model, and -0.045 to -0.189 for $B^{\prime}$ of the Parker-Santeler model. In particular, the regression coefficients of data set three vary most from those of data sets one and two. Data set three differed from one and two by an orifice area four times greater.

A similar comparison, by way of a regression analysis, was not made with the Borisov et al. model because i:s primary applicability is limited to the low pressure region of transitional flow.

When evaluating the success of the proposed model in comparison with other documented models, the model simplicity as well as accuracy must be considered. The proposed model has the advantage over the Borisov et al. model of application throughout the entire transitional region due to its dependency on both the free molecular and isentropic expansion models. The evidence indicates that the proposed model has improved accuracy over the Parker-Santeler model while making use of only a single regression coefficient. A particularly attractive aspect 
of the proposed model is its simplicity. The single regression coefficient has the advantage of producing a model whose semitheoretical origins are easily understood.

\section{NOMENCLATURE}

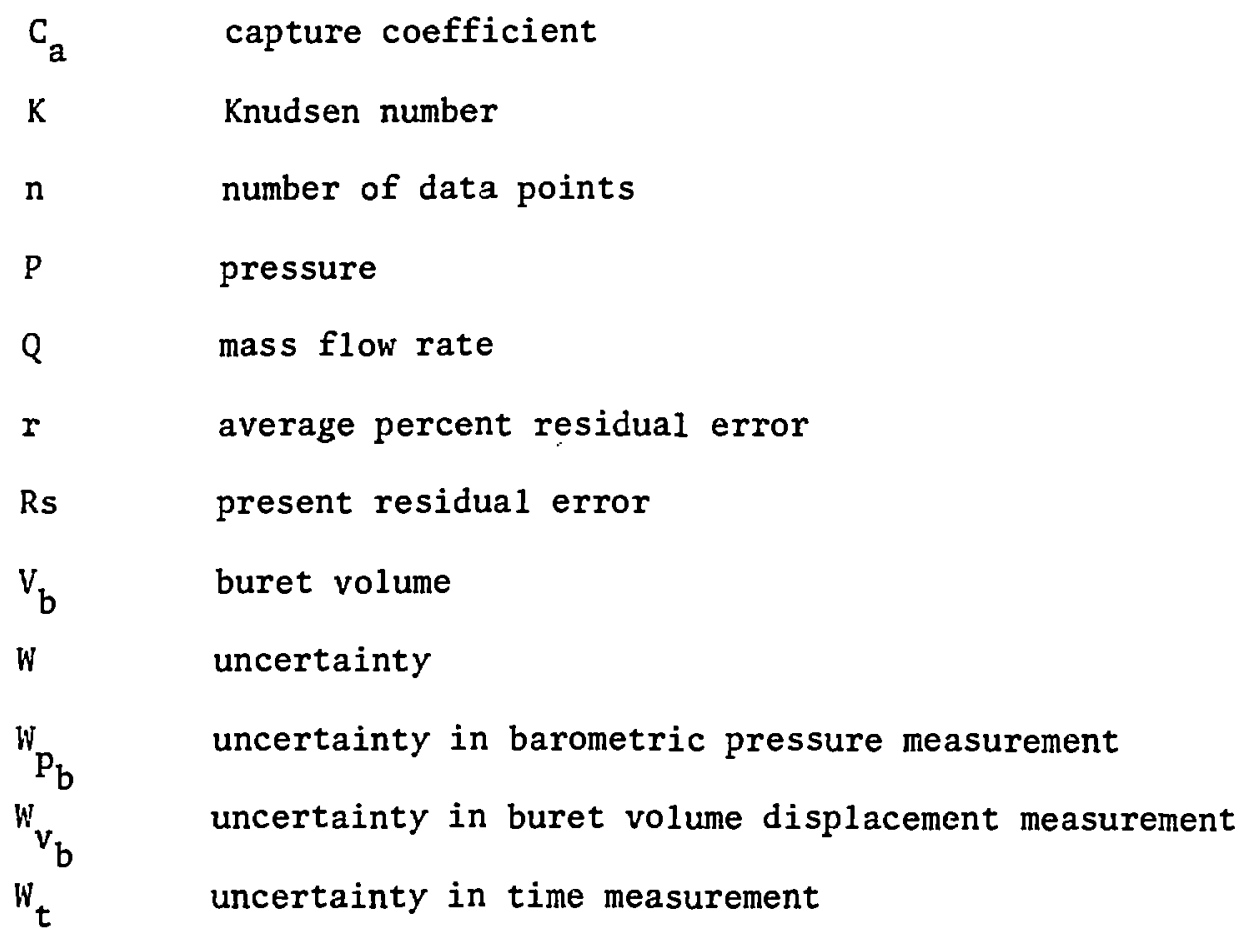

\section{Subscripts}

b barometric

d downstream

i isentropic

m free molecular

$t$ transitiona1

u upstream 


\section{REFERENCES}

1. R. C. Parker and D. J. Santeler, Vacuum Components Testing, performed for the Department of Energy under Contract EW-78-C-05-5646, Exxon Nuclear Company, Malta, N.Y., 1982.

2. S. F. Borisov, I. G. Neudachin, B. T. Porodnov, and P. E. Suetin, "Flow of Rarefied Gas Through an Orifice at Small Pressure Differentials," J. Tech. Phys. 18, 1092-94 (1974).

3. A. Roth, Vacuum Technology, 2nd ed., North-Holland Pub1ishing Company, New York, 1982.

4. S. F. DeMuth, Orifice Flow Modeling at the Free Molscular to Macro Thermodynamic Transition, Master of Science thesis at the University of Tennessiee, August 1985.

\section{DISCLAIMER}

This report was prepared as an account of work sponsored by an agency of the United States Government. Neither the United States Government nor any agency thereof, nor any of their employees, makes any warranty, express or implied, or assumes any legal liubility or responsibility for the accuracy, completeness, or usefulness of any information, apparatus, product, or process disclosed, or represents that its use would not infringe privately owned rights. Reference herein to any specific commercial product, process, or service by trade name, trademark, manufacturer, or otherwise does net necessarily constitute or imply its endorsement, recommendation, or favoring by the United States Government or any agency thereof. The views and opinions of authors expressed herein do not necessarily state or reflect those of the United States Government or any agency thereof. 